\title{
Nature and Incidence of Bullying among Nurses in Mississippi
}

\author{
Melody L. Fortune, Ph.D. \\ Associate Professor in Health Care Administration \\ Delta State University \\ Conrad Yelsong Puozaa, Ph.D. (corresponding author) \\ Assistant Professor of Management \\ Delta State University \\ Tomeka Harbin, Ph.D. \\ Associate Professor of Management \\ Delta State University
}

\begin{abstract}
This study sought to shed light on the issue of workplace bullying in the health care sector by investigating the experience and knowledge of workplace bullying among nurses in Mississippi, where health outcomes remain among the lowest in the country. Based on a sample of 897 nurses in the state, we examined nurses' familiarity with workplace bullying, the forms of bullying, and the perpetrators of bullying. Through descriptive statistical methods and logistic regression, we found that that the incidence of workplace bullying was higher in Mississippi compared to other states; females are disproportionately bullied; perpetrators of bullying were fellow nurses; nurses familiar with workplace bullying were more likely to spot and report it. Specifically, 98.7\% of respondents were at least somewhat familiar with workplace bullying. Of the $61 \%$ of respondents who were either targets or witnessed bullying, "verbal abuse" (more than 70\% mentions) was the most common form of bullying, while physical abuse was the least popular form of bullying (only $2 \%$ of mentions). For over $60 \%$ of targets, at least six months of bullying duration was common. From the multivariate logistic regression, the odds of being bullied were between 1.56 and 3.84 times higher for women than they were for men depending on the model specification. From these findings, it is clear that any anti-bullying measures should target all nurses and the organizational culture since the perpetrator is usually a fellow nurse.
\end{abstract}

Keywords: bullying, logistic regression, nurses, Mississippi

DOI: $10.7176 / \mathrm{JHMN} / 91-10$

Publication date:July $31^{\text {st }} 2021$

\section{Introduction}

The research on workplace bullying is quite expansive but the health care sector is yet to get the needed attention (Dellasega, 2009). Many studies in the sector have also tended to focus on new nurses. Despite this focus, its incidence may be more widespread among all categories of nurses. Understanding workplace bullying and how it relates to nurses, in particular, is very important in promoting and preserving a sound health system. Nurses often serve as the main link between a patient and his or her health care needs. Targets of bullying suffer emotional and physical distress that may lead to increased errors and decreased patient satisfaction rates (Thompson \& George, 2016; Meires, 2018; Lachman, 2015). Bullied nurses may also choose to abandon their profession altogether. For instance, Bowles and Candela (2005) reported that $30 \%$ of new nurses in Nevada left their jobs in the first year, and $57 \%$ had left by the second year.

Despite all that has been written about bullying, when it comes to what constitutes "workplace bullying" the jury is still out there. Workplace bullying has not been clearly articulated whether at the federal or state level. However, in some cases, if the bullying is based on race, gender, ethnicity, disability, or religion, individuals may be protected by Title VII of the Civil Rights Act of 1964. Although there are no universal set of laws that addresses workplace bullying, most state laws, policies, and regulations require school districts to implement antibullying policies (Stuart-Cassel et al., 2011). The following literature provides a glimpse of workplace bullying, legislation pertaining to workplace bullying, and the impact workplace bullying has on the health care sector.

\section{Workplace Bullying}

There are slight variations when it comes to the definition of workplace bullying in the literature. Workplace bullying is seen as a situation in which an individual, over a long period of time, is exposed to negative actions in which he or she is defenseless (Torok et al., 2016). Morrison (2020) sees it as a form of psychological violence that can cause harm to the target's or (and) target's family. The Workforce Bullying Institute (WBI) defines workplace bullying as the repeated, health-harming mistreatment of one or more persons 
(the targets) by one or more perpetrators. Fletcher (2015) is much bombastic in his view of workplace bullying as a form of organizational violence. Verkuil et al. (2015) describes workplace bullying as situations in the workplace where an employee persistently and over a long period of time perceives him- or herself to be mistreated and abused by other members of the organization for which she works for. The mistreatment is often psychological rather than physical (Flectcher, 2015; Verkuil et al., 2015). Carbo and Hughes (2010) on the other hand tried to define workplace bullying in a rather unique way: using the experiences of victims to determine its key elements. They found repetitiveness, severity, and power differential as the elements of bullying. They also differ on the time dimension included in other definitions of the concept. In their view, a single incident may have as much an impact as repeated incidents on the individual. Specifically, they reject the notion of bullying as "repeated actions".

These definitions highlight a number of common threads. Despite the rejection of the "repeated actions" over time by Carbo and Hughes, the definitions highlight that to be bullied at work, a worker must be subjected to repeated unreasonable behavior by an individual or group of individuals and excludes mere misunderstandings between individuals. Thus, the operational definition of workplace bullying for this research, which arises from these different views of the concept, refers to an unreasonable behavior by a person (or group of people) that intimidates, degrades, offend humiliates a worker. It can negatively affect the physical and mental health of the targeted worker. It is typically repeated unreasonable actions. It is not bullying when people disagree.

\section{Bullying and the Law}

Even with the increased prevalence of workplace bullying, there are no state and federal laws enacted to combat these disruptive behaviors. Bringing forward a complaint within civil law has proven to be a losing battle for plaintiffs (Tomkowicz \& Florentino, 2017). Findings from the "Status of Workplace Bullying in Federal Court Cases" report provide evidence in support Tomokwicz and Florentino's claim: the injured party rarely receives retribution for bringing a complaint to the court. The report shows that out of 93 court cases- 9 U.S. Courts of Appeal and 84 from U.S. District Courts- that referenced workplace bullying, only 3 cases were adjudicated in favor of the plaintiff.

While the courts have paid attention to cases involving physical assault, this has not been the case when it comes to the more prevalent form of bullying, verbal and other nonphysical forms of abuse. Consequently, a claim for infliction of emotional distress is typically not seen as a tort of assault, because the employee cannot reasonably prove the perceived imminent threat of bodily injury. In "Chinnery v. New York State Office of Children and Family Services" for instance, the court concluded that "mere" workplace bullying is not enough to give rise to an actionable hostile work environment claim. They argued that bullying can be said to have occurred if the target belongs to the "protected class". In some situations, the cases remained in the courts for years (Richardson et al. 2016).

The Supreme Court has not also been helpful when it comes to setting precedent involving workplace bullying. The Court has rather suggested that the lawsuits are an attempt to create a "civility code for the American workplace.” (see Oracle v. Sundowner Offshore Servs., Inc., 523 U.S. 75, 80, 118 S. CT. 998,140 L.Ed.2d 201 (1998)). As a result, the Sixth Circuit has repeatedly referenced this to pass judgment in favor of employers (Richardson et al. 2016).

Some states are taking measures to address workplace bullying. California and Tennessee are several steps ahead of the other 23 states in the legislative process. In 2003, California enacted the Healthy Workplace Bill (HWB) which at its core made an "abusive work environment" an unlawful employment practice. This exists when an employer or one or more of its employees acting with intent to cause pain or distress to an employee, subjects that employee to abusive conduct that causes physical harm, psychological harm, or both (Yamada, 2015). This law essentially requires businesses with 50 or more employees to review two hours of harassment education within six months of being promoted to a supervisory position. The California HWB was adopted by Tennessee in 2015 .

\section{Bullying Among Nurses}

Bullying is widespread and health care workers have had their share. In a meta-analysis of 136 articles that included studies from 38 countries, and over 151,347 health care workers, Spector et al. (2014) found that $23 \%$ of nurses had been bullied in the prior 6 months, $47 \%$ had been bullied in the prior year, and $70 \%$ had been bullied at some point in their careers. Lever et al. (2019), suggest that bullying is more frequent in the health care sector than in any other sector. They explain that the high prevalence of bullying in the sector may be due to the interpersonal and emotional nature of the job; the hierarchical make-up of health care organizations; and the conflicting objectives of multidisciplinary teams.

Despite its prevalence, the occurrence of bullying in the sector is not uniform across ranks or space. For instance, Lee et al. (2014) find that nurses report being bullied more than any other class of workers in the health 
and Bowles and Candela (2013), find that newly licensed nurses are more predisposed to the effects of nurse bullying than experienced nurses. Reports of nurses in lower ranks being the target of bullying firm came to fore as result of a New York Times publication in 1909. The article described in detail, the observations of two doctors on the negative behaviors of head nurses towards their student nurses. This article portrayed head nurses as dictators and tyrants to the nurses they were responsible for. Some scholars speculate that the 1909 article is the focal point for the term "nurses eat their young" (Meires, 2018).

In a more recent study, many nursing students experience bullying during clinical rotations. According to Clarke et al. (2012), 88\% of nursing students $(n=674)$ reported experiencing bullying behaviors during their clinical. Similarly, Thompson and George (2016) report that newly licensed nurses are more likely to be victims than their experienced counterparts. In 2014, over 2000 nursing graduates were surveyed with results indicating $39 \%$ of the nurses reported being bullied at work or subjected to a hostile work environment (Kaplan, 2014).

Nurses are a key part of health care delivery and retaining them must be in the interest of all. Certainly, a toxic work environment as a result of the prevalence of bullying does not help. Bullying, unfortunately, does not occur uniformly across states and sectors. Therefore, it is imperative that any policies aimed at curbing the phenomenon be guided by sound studies in the state or sector. In places like Mississippi where the per capita qualified medical care personnel is low, issues of bullying and any other negative work-related hindrances need to be addressed. As one of the poorest states, the direct cost of replacing nurses can be a costly exercise for the state. It takes around $125 \%$ of a nurse's annual salary to replace a nurse who has left their job (Stagg \& Sheridan, 2010).

Apart from the direct cost of replacing nurses, the health profile of Mississippi residents makes it an even ever pressing need to attract retain nurses. The state happens to have some of the worse health care outcomes in the country. In 2016, diabetes was the seventh leading cause of death, with a rate of $33.9 \% ; 40.9 \%$ of the people surveyed in the BRFSS survey indicated being told they had high blood pressure; $37.5 \%$ of the respondents were obese. People who are overweight increase their risk of illness from multiple diseases such as "hypertension, high cholesterol, Type 2 diabetes, heart disease, and stroke, gall bladder disease, cancer of the endometrium, breast, colon, and prostate as well as arthritis" (Centers for Disease Control and Prevention, 2017). With the risk for increased negative health outcomes being prevalent, understanding how bullying impacts nurses in Mississippi is significant.

Thus, the current study determines whether nurses in Mississippi are knowledgeable about bullying; and whether they have experienced or witnessed bullying. This study seeks to answer two research questions: 1 . Is bullying as prevalent in Mississippi as it is in other places? 2. Are some categories of nurses more likely to be bullied than others?

\section{Methods}

This study collected data through an anonymous survey, with the target population being all practicing registered nurses in Mississippi, using the Survey Monkey platform. The Listserve of nurses licensed in the state of Mississippi was purchased from the Mississippi Board of Nurses (MBS). The Listserve contained physical and email addresses of members. The entire population in the sampling frame was considered eligible for inclusion. However, since the survey was administered via email, only nurses with valid email addresses were contacted. According to the National Council of State Boards of Nursing (NCSBN), there were approximately 65,000 nurses in Mississippi in 2018. The Mississippi contact list from the MBS contained approximately 45,000 email addresses. Of this number, 20\% were invalid email addresses. Of the remaining 34,898 people emailed, 921 responded to the survey. Responses from another 24 people were not included in the study because 22 stated that they no longer practiced nursing and the other two did not complete the survey. The final dataset comprised of 897 nurses.

The survey was funded by the College of Business and Commercial Aviation at Delta State University (DSU). The survey instrument contained 27 questions looking at respondents' knowledge and experience(s) of bullying, effects of bullying on targets, and redress mechanisms. The survey was administered from January 1, 2018, through April 1, 2019. To ensure anonymity, sensitive information such as name, place of work, address, or any such identifiers was not collected. The study was exempt from full Institutional Review Board (IRB). The DSU IRB approval number is IRB00011020.

The final sample of 897 was comprised of $92 \%$ women and $8 \%$ men. By way of the type of nurses, $13.4 \%$ of the sample are nurse practitioners with (NP), $46.4 \%$ are registered nurses with a bachelor's degree in nursing (BSN), and the remaining 40.2\% are registered nurses without a bachelor's degree (ADN).

Before answering specific questions on workplace bullying, each respondent had to indicate his/her level of familiarity with the concept, "Workplace Bullying". Likert scale of 1-4 (1-Not familiar, 2- Somewhat familiar, 3- Familiar, and 4- Very familiar). The following questions were included: "Workplace Bullying refers to an unreasonable behavior by a person (or group of people) that intimidates, degrade, offend or humiliates a worker. It can negatively affect the physical and mental health of the targeted worker. It is typically repeated, 
unreasonable actions. It is NOT bullying when people disagree." Bullying target was assessed using a binary scale $(0=$ "No, I have never been a victim of bullying" or $1=$ "Yes, I have been a victim of bullying").

Simple ratios were used to summarize and compare responses. For the multivariate analysis, a logistic regression model was used to calculate the adjusted odds ratios (ORs) and associated confidence intervals (CIs) at $95 \%$. The study significance level was set at $\mathrm{p}<.05$. The authors used Stata software, Version 14 , for Windows (StataCorp LP, College Station, TX, USA) for the multivariate analysis.

\section{Results}

We first investigate respondents' awareness of the concept of workplace bullying. On the question of respondents' familiarity with "workplace bullying", only $12(1.3 \%)$ of the 897 respondents were not familiar with the concept. The remaining $98.7 \%$ of respondents were at least somewhat familiar with the definition: 8.6\%-" "Somewhat", 29\%- "Familiar" and 61.1\%-"Very familiar".

Bullying targets were mostly women. In all, $62 \%$ of women and $51 \%$ of men reported having been bullied. The percentage of nurses reporting to have been bullied was nearly the same among different types of nurses, $63.3 \%$ for nurse practitioners, $60 \%$ for registered nurses with a bachelors and $64.5 \%$ for registered nurses without a bachelors. Based on respondents' familiarity with the term and the target of bullying, 33\% (68.8\%) of those unfamiliar ("Very familiar") with the term said they experienced or witnessed bullying. Table 1 summarizes responses based on gender, familiarity with bullying, and whether the respondent was bullied or not.

With respect to the perpetrator of workplace bullying, both vertical and horizontal perpetrators were reported. Bullying was classified as horizontal when the offender was a coworker of the same hierarchical level as the victim (Lopes, 2012; Carvalho, 2006). Figure 1 summarizes the number of mentions received by different bully perpetrators. "Fellow nurse" is the most mentioned perpetrator of bullying. This is true for nurses who were targets of bullying themselves and those who observed another nurse being bullied. Figure 2 shows the share of mentions for each perpetrator of bullying. While "A fellow nurse" was mentioned about $64 \%$ of the time, "A doctor" and "A supervisor" recorded lower mentions. Doctors were mentioned around $40 \%$ of the time while supervisors came around $50 \%$ for self-reporting victims. Reports from observers of bullying are similar except in the case of supervisor-perpetrator; supervisor as the perpetrator was mentioned $37 \%$ of the time.

The targets of bullying were subjected to many forms of bullying at the same time. The most common forms of bullying among nurses in the state were verbal abuse, threats, and humiliation. Of the $61 \%$ of respondents who were either targets or witnessed bullying, "verbal abuse" (more than 70\% mentions) was the common form, followed by "humiliation" and "threats." Figure 2 compares bullying types as reported by those who witnessed and those who suffered bullying directly. The widest variation based out witnesses and actual targets had to do with threats. While observers of bullying mentioned a "threatening attitude" $61.5 \%$ of the time as the form of bullying, actual targets mentioned this $48 \%$ of the time. Physical abuse as a form of bullying was low: around $2 \%$.

The duration of bullying was expressed as 1-2 months or less, 2-5 months, 6-12 months, and more than 1 year in the questionnaire. More than $60 \%$ of respondents who reported having been bullied or witnessed another person being bullied, reported bullying duration of at least six months. Only 19\% of targets or witnesses reported a bullying duration of fewer than two months. The remaining $21 \%$ (or 113 ) reported a $2-5$ months period.

The findings of the multivariate logistic regression with the dichotomous dependent variable, "bullied", are presented in Table 2. The odds ratios for the associations between bullying status (whether bullied or never bullied) and other covariates: type of nurse, gender, and familiarity with workplace bullying. While Table 1 shows a slightly higher percentage of BSN-type nurses reporting to have been bullied, the regression results show that this outcome is not statistically significant. Thus, the likelihood of being bullied does not change based on nurse type. In Model 2 and Model 3, this result remains the same even when we control for other variables.

The results, however, show a significant increase in risk for female nurses than their male counterparts in all models. The odds of being bullied were at least 1.56 times higher for women than they were for men. In Model 3, we include respondents' familiarity with bullying, and the likelihood of being bullied is still higher for women (1.65 times higher).

Model 3 shows that respondents who are more familiar with the concept of workplace bullying were more likely to be bullied. The odds of being bullied are 2.03 times higher for nurses "familiar" with the concept of workplace bullying than for those "unfamiliar" it. The odds are even higher (3.84) in the case of nurses who are "very familiar" with the concept, compared to those "unfamiliar" with the concept. 


\section{Discussion}

This is the first study on workplace bullying among nurses in Mississippi. In this study, the theoretical definition of bullying was presented to participants before following up with questions about their experience of the phenomenon: whether they had been targets or witnesses of bullying. The type and quality of methods used to measure the prevalence of bullying have varied across previous studies. When using a self-reported approach, the respondents' perceptions were assessed via a question about whether respondents had been bullied. A "No- I have not been bullied" response to this question leads to a follow-up question on whether the respondent had witnessed bullying.

The prevalence of bullying can be influenced by several factors. The incidence of bullying can be influenced by how the concept is defined and measured, the survey and indeed, the research design, cultural characteristics, and social change can also explain variations in prevalence rates (Nielsen et al., 2012). The prevalence reported in this study was higher than the prevalence observed in the other two states where similar studies have been undertaken: $27.3 \%$ (of 249 members) among emergency nurses in Washington State and $31 \%$ in Massachusetts (Simons, 2006). For the entire U.S., Dunn (2003) reported that $38 \%$ of health care employees reported psychological harassment. The higher reported prevalence of bullying in this study may be explained by the higher level of awareness of bullying that might have occurred among the general population in recent times, helped by HWB in neighboring state, Tennessee since 2014, and the Me Too Movement in the last two years. As indicated in Table 1, it appears familiarity with workplace bullying increases the chance of spotting it when occurs. For instance, while $33.3 \%$ of those unfamiliar with workplace bullying reported, $68.8 \%$ of those very familiar with the concept reported. Indeed, a $61 \%$ prevalence rate among all nurses in the state indicates that bullying is a serious problem for a substantial number of nurses, and steps must be taken to address the problem.

The result that a fellow nurse was mostly the perpetrator, is interesting. Respondents who were bullied stated that a fellow nurse was the perpetrator $65 \%$ of the time. To check the validity of this claim, responses from bullying targets were compared to witnesses of bullying. The data demonstrated that witness accounts mimicked those of actual victims; workplace bullying was not carried out by supervisors and superiors alone. The perpetrator was usually a fellow nurse $(60 \%$ of the time). This is contrary to findings from previous studies. In the case of Washington State, $61 \%$ of respondents who indicated that they had been bullied stated that they were bullied by a superior. A nurse bullying a fellow nurse may be explained by the high level of stress on the job (Edmonson \& Zelonka, 2019), the prevalence of shift work (Norton et al. 2017; Carvalho, 2010), and the intensity of supervision from supervisors (Carvalho, 2010).

The nature of the occurrence of bullying in the state presents some positive suggestions for dealing with workplace bullying. Since bullying is among peers, this finding implies that targets should have a relatively easier time enlisting the support of their superiors to end bullying, all things equal. In this direction, Johnson and Rea (2009) suggest that anti-bullying measures should target nurse leaders to change any organizational elements that support bullying. A change in organizational culture is important, otherwise, there is a great likelihood that the bullied would suffer in silence.

As far as the nature of bullying is concerned, this research analysis showed that $2.3 \%$ of targets declined to state the type of abuse while around $2 \%$ of witnesses of bullying refused to state the type of abuse. This was likely due to the traumatic nature of bullying (Tye-Williams and Krone, 2015). Further research is needed to explore this.

All workers have the right to work in an environment that is free from hostility. Yet, there are no federal laws directly dealing with workplace bullying. Title XII of the Civil Rights Act provides some protections for individuals, but only if they are in one of the protected classes. Although 29 states and 2 territories have introduced the HWB, none have passed the full bill. HWB, among other things, clearly defines an "abusive work environment" and "plugs the gaps in current state and federal civil rights protections" (Healthy Workplace Bill, 2014).

This study is not without limitations. The nature of the phenomenon being studied here means that the results of this study should be generalized to include nurses in all states. This quantitative cross-sectional study identified the likelihood of being bullied among nurses in Mississippi. The dataset used in this study is not static but dynamic; depends on the external and internal forces surrounding the individual's workplace. Therefore, the survey data may have limited value to other states within the country. The study sample for the study also relied on email addresses from the Mississippi Nurses Association. The survey did not reach members whose email addresses were incorrect or did not have email addresses on file. However, there is no reason for the researchers to believe that members without email addresses were systematically targeted. A smaller but more extensive 
study may be important to serve as a baseline and offer guidance to future research design on the problem of bullying in the state.

\section{Implications for Occupational Health Nursing Practice}

Bullying is widespread in Mississippi based on evidence from this study. Apart from all the negative effects on the nurse and her own work output, it is costly to the state in terms of both replacement of nurses and health outcomes. Therefore, all stakeholders must be interested in curbing the phenomenon of workplace bullying; it cannot be left in the hands of just targets and supervisors. The state, nurse supervisors and the leadership of health care facilities and personnel in general must put strategies in place that curb the phenomenon. Any such strategies should also include programs that create awareness about the phenomenon and its effects of bullying on targets. Perpetrators need to understand that the effects of their behaviors go beyond their target; their behavior indirectly puts the wellbeing of people seeking medical attention at risk.

\section{Conclusion}

The purpose of this study was to examine the nature of the incidence of bullying on nurses in Mississippi. The study sought to determine nurses' familiarity with workplace bullying, the forms, and duration of bullying, perpetrators of bullying, and the experience of bullying. The majority of respondents were familiar with the term bullying and had experienced or witnessed bullying in the workplace. Statistical analysis shows that women are more likely to be bullied and the likelihood of reporting bullying increases with a respondent's familiarity with the term, workplace bullying. In addition, perpetrators were mostly fellow nurses and not necessarily from other categories of employees as has been found in other studies. It is incumbent upon health care facilities to adopt a zero-tolerance to bullying and create a zone where victims of bullying feel empowered to report bullying tactics and workplace violence.

\section{Applying Research to Practice}

This research does not only highlight the widespread incidence of workplace bullying, it also underscores the need for more localized studies to understand the phenomenon. Nurses need to understand what constitutes bullying and its effects on targets. But truly combating bullying must be the responsibility of all stakeholders. States (and the federal government) must create the legal regime that frowns on bullying in the health sector, in particular. Nurses, their supervisors and hospital administrators need to ensure that bullying is not persistent.

They should be educated to recognize, report and address bullying immediately it occurs because with bullying,

\section{REFERENCES}

Bowles, C., \& Candela, L. (2005). First job experiences of recent RN graduates: improving the work environment. JONA: The Journal of Nursing Administration, 35(3), 130-137.

Carbo, J., \& Hughes, A. (2010). Workplace Bullying: Developing a Human Rights Definition from the Perspective and Experinces of Targets. The Journal of Labor and Society, 387-403.

Carvalho, M. (2006). Moral harassment/mobbing. Revista dos Técnicos Oficiais de Contas, 77, 40-49

Carvalho, G. D. (2010). Mobbing: Moral harassment in a nursing context. Revista Investigação de Enfermagem, $21,28-42$

Centers for Disease Control and Prevention, Behavioral Risk Factors Surveillance System. (2017). Mississippi State Department of Health. Retrieved from ttp://msdh.ms.gov/brfss/brfss2009ar.pdf

Clarke, C. M., Kane, D. J., Rajacich, D. L., \& Lafreniere, K. D. (2012). Bullying in undergraduate clinical nursing education. Journal of Nursing Education, 51(5), 269-276.

Dellasega, C. A. (2009). Bullying among nurses. AJN The American Journal of Nursing, 109(1), 52-58.

Dunn, S. (2003). What's going on with mobbing, bullying and work harassment internationally.Bellingham, WA: Workplace Bullying Institute. Retrieved http://wwwworkplacebullying.org/press/wepronews.html

Edmonson, C., \& Zelonka, C. (2019). Our own worst enemies: the nurse bullying epidemic. Nursing administration quarterly, 43(3), 274.

Fletcher, S. (2015, November). Workplace bullying: The endgame. In European Conference on Management, Leadership \& Governance (p. 113). Academic Conferences International Limited. 
Johnson, Susan L, Boutain, Doris, Hsin-Chun Tsai, Jennny, Beaton, Randal and de Castro, Arnold B. (2015) An Exploration of Managers' Discourses of Workplace Bullying. Nursing Forum, Volume 50, No 4, October-December 2015.

Kaplan Survey: Nearly Half of Recent Nursing School Graduates Are Concerned About Working in a Hostile Environment or Becoming Victims of Workplace Bullying: Kaplan Test Prep. (2014, August 28). Retrieved from https://www.kaptest.com/blog/press/2014/08/28/kaplan-survey-nearly-half-of-recentnursing-school-graduates-are-concerned-about-working-in-a-hostile-environment-or-becomingvictims-of-workplace-bullying/

Lachman, V. (2015). Ethical issues in the disruptive behaviors of incivility, bullying, and horizontal/lateral violence. Urologic Nursing, 35(1), 39-42.

Lee, Y. J., Bernstein, K., Lee, M., \& Nokes, K. M. (2014). Bullying in the nursing workplace: Applying evidence using a conceptual framework. Nursing Economic\$, 32(5), 255-267.

Lever, I., Dyball, D., Greensberg, N., \& Stevelink, S. (2019). Health consequences of bullying in the healthcare workplace: A systematic review. JAN Leading Global Nursing Research.

Lopes, L. N. (2012). Moral harassment in time of crisis. Revista Segurança, 207, 7.

Meires, J. (2018). The essentials: Here's what you need to know about bullying in nursing. Society of Urologic Nurses and Associates, 38(2), 95-97, 102.

Meires, J. (2018). The essentials: Using emotional intelligence to curtail bullying in the workplace. Society of Urologic Nurses and Associates, 38(3), 150-153.

Morrison, Eileen E. (2020). Ethics in Health Administration (4th Edition). ISBN-978-1-284-15611-9.

Nielsen, M. B., Hetland, J., Matthiesen, S. B., \& Einarsen, S. (2012). Longitudinal relationships between workplace bullying and psychological distress. Scandinavian Journal of Work, Environment \& Health, $38,38-46$.

Norton, P., Costa, V., Teixeira, J., Azevedo, A., Roma-Torres, A., Amaro, J., \& Cunha, L. (2017). Prevalence and determinants of bullying among health care workers in Portugal. Workplace health \& safety.

Richardson, R., Joiner, S., \& Hall, R. (2016). The Status of Workplace Bullying in Federal Court Cases. Academy of Business Research Journal, 117-131.

Simons, S. R. (2006). Workplace bullying experienced by nurses newly licensed in Massachusetts and the relationship to intention to leave the organization (Doctoral dissertation, University of Massachusetts Boston).

Spector, P. E., Zhou, Z. E., \& Che, X. X. (2014). Nurse exposure to physical and nonphysical violence, bullying, and sexual harassment: A quantitative review. International Journal of Nursing Studies, 51(1), 72-84.

Stagg, S. J., \& Sheridan, D. (2010). Effectiveness of bullying and violence prevention programs. Workplace Health \& Safety, 58, 419-424.

Stuart-Cassel, V., Bell, A., \& Springer, J. F. (2011). Analysis of State Bullying Laws and Policies. Office of Planning, Evaluation and Policy Development, US Department of Education.

Thompson, R. \& George, L. E. (2016). Preparing new nurses to address bullying: The effect of an online educational module on learner self-efficacy. MEDSURG Nursing, 25(6), p. 412-417.

Tomkowicz, S. M., \& Florentino, S. R. (2017). Status-Blind Harassment and the Faragher Model: A Comprehensive Managerial Response to Workplace Bullying. Southern Law Journal, 1-34.

Torok, E., Hansen, A. M., \& Grynderup, M. B. (2016). The Association Between Bullying and Depressive Syptoms: The Role of the Perpetrator. BioMed Central Journals.

The New York Times. (1909, August 22). The hospital tyrants and their victims, the nurses. What doctors say of the oppression of young women in these institutions. The New York Times. (SM8)

Tye-Williams, S., \& Krone, K. J. (2015). Chaos, reports, and quests: Narrative agency and co-workers in stories of workplace bullying. Management Communication Quarterly, 29(1), 3-27.

Verkuil, B., Atasayi, S., \& Molediijk, M. L. (2015). Workplace Bullying and Mental Health: A Meta-analysis on Cross Sectional and Longitudinal Data. Public Library of Science.

Vartia, M. A. (2001). Consequences of workplace bullying with respect to the well-being of its targets and the observers of bullying. Scandinavian journal of work, environment \& health, 27(1), 63-69.

Wiedmer, Terry L. (2011). Workplace Bullying: Costly and Preventable. Morality in Education, Winter 2011.

Yamada, D. C. (2015). lWorkplace Bullying and the Law: U.S. Legislative Developments 2013-15 . Suffolk University Law. 
Table 1: Summary Data

\begin{tabular}{|l|l|l|}
\hline & $\%(\mathrm{n})$ & $\%(\mathrm{n})$ Bullied \\
\hline Gender & & \\
\hline Male & $8 \%(74)$ & $51 \%(38)$ \\
\hline Female & $92 \%(823)$ & $62 \%(513)$ \\
\hline & & \\
\hline Job Category & & \\
\hline$N P$ & $13.4 \%(120)$ & $63.3 \%(76)$ \\
\hline$B S N$ & $46.4 \%(416)$ & $60.6 \%(252)$ \\
\hline ADN & $40.2 \%(361)$ & $64.5 \%(223)$ \\
\hline & & \\
\hline Familiarity with bullying & & \\
\hline Not familiar & $1.3 \%(12)$ & $33.3 \%(4)$ \\
\hline Somewhat & $8.6 \%(77)$ & $37.7 \%(29)$ \\
\hline Familiar & $29 \%(260)$ & $54.2 \%(141)$ \\
\hline Very familiar & $61.1 \%(548)$ & $68.8 \%(377)$ \\
\hline
\end{tabular}

A summary of the survey data showing the number of respondents (and share of total responses) in column 2 and bullying status in column 3 .

Table 2: Odds Ratios from Logistic Regression of bullying status

\begin{tabular}{llll}
\hline VARIABLES & Model 1 & Model 2 & Model 3 \\
\hline Nurse- Practitioner & & & \\
& 1.069 & 1.072 & 0.975 \\
Nurse- BSN & $(0.233)$ & $(0.234)$ & $(0.219)$ \\
& 0.951 & 0.955 & 0.878 \\
Female & $(0.140)$ & $(0.141)$ & $(0.134)$ \\
& & $1.566^{*}$ & $1.646^{* *}$ \\
Familiar with bullying & & $(0.266)$ & $(0.249)$ \\
& & & $2.033^{* * *}$ \\
Very familiar with bullying & & & $(0.515)$ \\
& & & $3.842^{* * *}$ \\
Constant & & & $(0.921)$ \\
& $1.616^{* * *}$ & 1.070 & $0.391^{* * *}$ \\
Observations & $(0.175)$ & $(0.266)$ & $(0.127)$ \\
\hline
\end{tabular}

Standard errors in parentheses

$* * * p<0.01, * * p<0.05, * p<0.1$

This regression shows the odds ratios from logistic regression with bullying status as the dependent variable. 


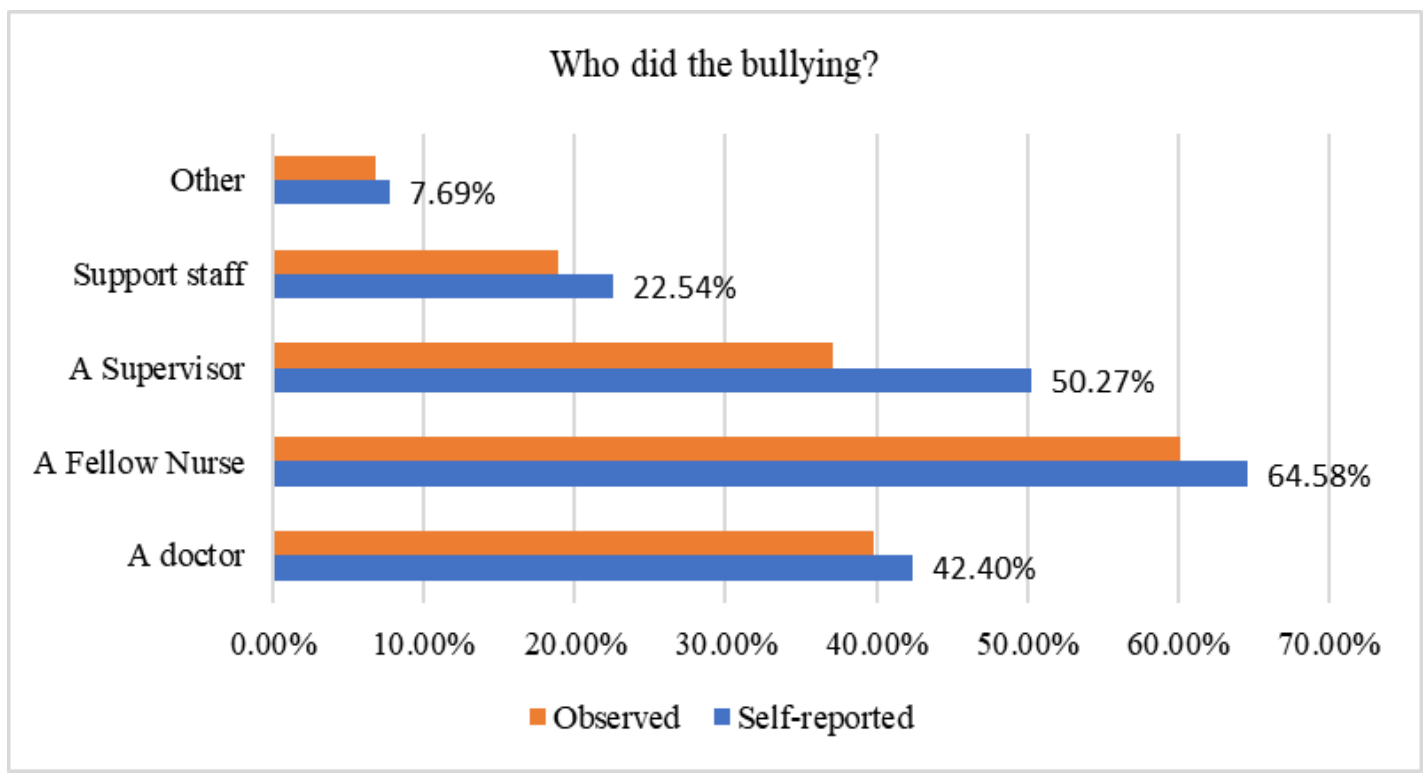

Figure 1 Perpetrator of bullying.

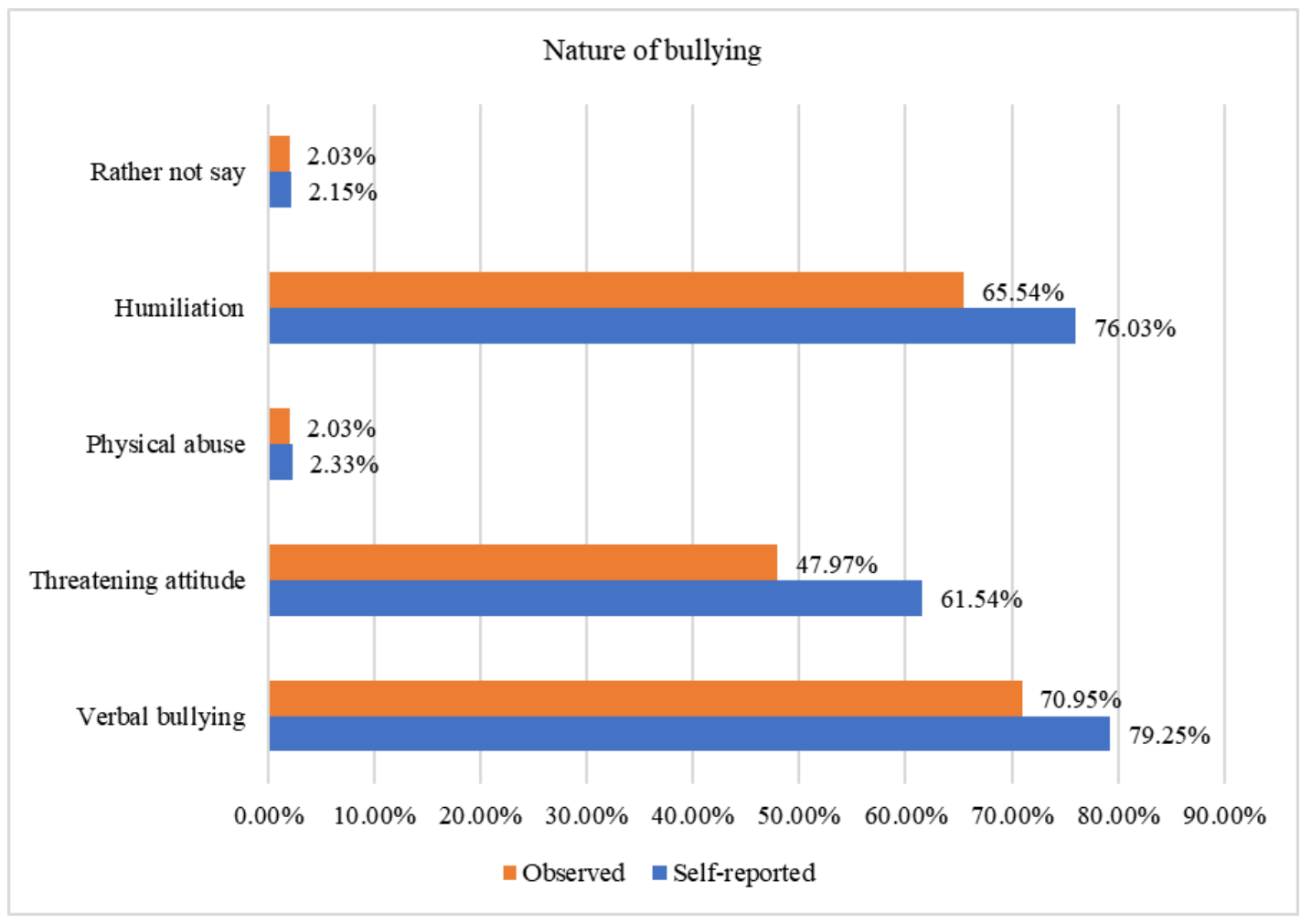

Figure 2 The type of bullying.

The figure shows the types of bullying among nurses profession in Mississippi. 